\title{
Modeling the Effect of Preharvest Weather Conditions on the Incidence of Soggy Breakdown in 'Honeycrisp' Apples
}

\author{
Maude Lachapelle and Gaétan Bourgeois ${ }^{1}$ \\ Saint-Jean-sur-Richelieu Research and Development Centre, Agriculture \\ and Agri-Food Canada, Saint-Jean-sur-Richelieu, QC J3B 3E6, Canada
}

Jennifer R. DeEII

Ontario Ministry of Agriculture, Food and Rural Affairs, Simcoe, ON N3Y 4N5, Canada

\section{Katrine A. Stewart and Philippe Séguin \\ Department of Plant Science, McGill University, Sainte-Anne-de-Bellevue, QC H9X 3V9, Canada}

Additional index words. phenology, disorders, forecast, stepwise regression

\begin{abstract}
Honeycrisp' is a relatively new apple cultivar highly susceptible to physiological disorders, such as soggy breakdown. The overall objective of this study was to identify preharvest weather parameters that influence the incidence of soggy breakdown over the different phases of fruit development. Using weather data and evaluation of fruit quality from three sites in Ontario, two sites in Quebec, and one site in Nova Scotia from 2009 to 2011, and data from four sites in Ontario from 2002 to 2006, a model for soggy breakdown incidence (SBI) was developed to predict the level of susceptibility in 'Honeycrisp' apples. This model uses primarily two weather variables during the last phase of fruit development [91 days from full bloom (DFB) to harvest] to accumulate an SBI index during the growing season, from full bloom to harvest. $\mathrm{Cool}$ (temperature $<5^{\circ} \mathrm{C}$ ) and wet conditions (precipitation $>0.5 \mathrm{~mm}$ ) during this last phase resulted in increased soggy breakdown susceptibility levels. The predictions of the SBI model resulted in $68 \%$ of well-estimated cases (threshold of $\pm 5 \%)(\mathrm{RMSE}=6.45, \mathrm{EF}=0.28, E=-0.04)$. Furthermore, firmness was linked to soggy breakdown, in addition to weather conditions, revealing a positive effect of high firmness at harvest on the development of the disorder. However, the effect of fruit quality attributes (e.g., internal ethylene concentration, starch index, firmness, and soluble solid content) by themselves, without considering weather conditions, revealed no relationship with the incidence of soggy breakdown.
\end{abstract}

Soggy breakdown is a chilling-related disorder, which in worse cases forms a soft, brown, spongy tissue in the outer apple cortex. It is known to affect the quality of 'Honeycrisp' apples, a new variety that is gaining popularity because of its high firmness maintained during storage, good coloration,

Received for publication 11 Mar. 2016. Accepted for publication 3 Oct. 2016.

This article is part of a thesis submitted to the Faculty of Graduate Studies and Research in partial fulfillment of the requirements for the degree of Master of Science of Maude Lachapelle.

The authors would like to thank the Ontario Apple Growers and Norfolk Fruit Growers' Association for their support. We thank Behrouz Ehsani-Moghaddam, Emilea Smith, Dominique Plouffe, Danielle Choquette, and Pierre Dutilleul for their technical and statistical assistance. This project was funded by Agriculture and Agri-Food Canada. Maude Lachapelle was supported by the Research Affiliate Program (RAP) at Agriculture and Agri-Food Canada.

1Corresponding author. E-mail: Gaetan.Bourgeois@ agr.gc.ca. of 'Honeycrisp' apples to the development of soggy breakdown. Using multiyear weather data from a range of locations in eastern Canada, weather patterns were examined during the different phases of fruit development and linked to SBI.

A model exists for the risk index of lowtemperature disorders (LTD-riskV2), which was mainly built from observations of vascular browning in 'McIntosh' and 'Cortland' apples, developed with weather data from five regions in Quebec from 1977 to 1995, and implemented in the Computer Center for Agricultural Pest Forecasting (CIPRA) software (Bourgeois et al., 2014b). This model mainly uses functions that include maximum and minimum temperatures and solar radiation during the months of July and August. A daily risk index is calculated starting from the phenological stage of fruit set, providing prediction in real time of vascular browning risk during the growing season. Disorder risk predictions from this model, using weather data, were conducted for comparison with predictions from the soggy breakdown model developed in this study. Accurate predictions for soggy breakdown could be used by producers of 'Honeycrisp' apples to help establish their marketing and storage strategies considering regional and seasonal susceptibility to this disorder.

\section{Materials and Methods}

'Honeycrisp' apples were harvested from three commercial orchards in Ontario (Newcastle, Norfolk County, and Georgian Bay), one orchard in Nova Scotia (Kentville), and two orchards in Quebec (Franklin and Île d'Orléans), from 2009 to 2011. For each orchard location, two boxes containing about 60 fruits each were stored at $3{ }^{\circ} \mathrm{C}$ for 3 to 4 months at the Storage Research Laboratory in Simcoe (Ontario). Apples from Ontario and Quebec were transported and stored in the laboratory on the same day as harvest, and apples from Nova Scotia were transported within $3 \mathrm{~d}$ via refrigerated truck at $\approx 3{ }^{\circ} \mathrm{C}$. Data were also collected from an Ontario site (Norfolk Co.) from 2002 to 2006, as well as from four nearby sites (within $20 \mathrm{~km}$ ). For each orchard location, two boxes containing about 60 fruits each were stored the same day as harvest, although they were placed at $0.5-1.0{ }^{\circ} \mathrm{C}$ for 4 to 5 months to induce soggy breakdown.

Fruit quality analyses. Fruit quality attributes were evaluated at harvest and after 3 to 4 months in storage using the same protocol described by DeEll and Ehsani-Moghaddam (2010). The optimum harvest time for each site was estimated by fruit color, a change of background color from green to yellow, and starch index between 5 and 7, as determined by the Cornell Starch Chart (Blanpied and Silsby, 1992). At harvest, subsamples were analyzed for maturity. After 3 to 4 months in storage, 20 apples per site were evaluated for fruit quality, including incidence of soggy breakdown, whereas the remaining fruit 
( $\approx 30$ per location) were evaluated only for incidence of soggy breakdown.

Internal ethylene concentration was evaluated by extracting a $3-\mathrm{mL}$ gas sample from the core of each apple using a syringe and then injecting the sample into a Varian CP3380 Gas Chromatograph (Varian Canada Inc., Mississauga, ON) (DeEll and EhsaniMoghaddam, 2010). Starch index was determined using the Cornell generic starchiodine index chart for apples. Apples were cut in half at the equator and rated on a scale of 1 to 8 , where $100 \%$ starch staining is 1 and $0 \%$ is 8. Fruit firmness was evaluated on opposite sides of each apple using the electronic Fruit Texture Analyzer fitted with an $11.1 \mathrm{~mm}$ tip (Güss Manufacturing, Strand, South Africa), after removing the peel on each side. Titratable acidity (expressed as mg equivalents of malic acid per $100 \mathrm{~mL}$ of juice) was determined by titrating a $2-\mathrm{mL}$ juice sample (extracted from composite samples of segments from all apples used for firmness testing) with a $0.1 \mathrm{~N} \mathrm{NaOH}$ solution to an endpoint of $\mathrm{pH} 8.1$ (as indicated by phenolphthalein). Soluble solid concentration was determined using a digital BRX-242 Refractometer (Atago Co., Ltd, Japan). The apples were cut in half at the equator, and the incidence was determined by the presence or absence of soggy breakdown symptoms. Percentage of incidence was also calculated for each orchard location by presence or absence of the disorder, regardless of severity.

Monitoring and management of weather data. Weather data were collected from the Quebec Apple Network or the National Climate Data and Information Archive Network according to their proximity to the study orchards (Environment Canada, 2010; Sarrazin, 2006). For the two sites in Quebec, weather stations were located directly in the orchard. For the three sites in Ontario, weather stations selected were Delhi (Norfolk Co.), Cobourg (Newcastle), and Collingwood (Georgian Bay). In Nova Scotia, a weather station located directly in Kentville was selected. Information recorded from these stations included the following: hourly minimum, maximum and mean temperatures $\left({ }^{\circ} \mathrm{C}\right)$, relative humidity $(\mathrm{RH})(\%)$, and hourly and daily accumulated precipitation $(\mathrm{mm})$.

Data management and statistical analyses. Following the method used in the study of Moran et al. (2009), weather data from all weather stations were divided into phases of $30 \mathrm{~d}$ corresponding to apple growth development, according to the number of DFB until harvest. For each phase of fruit development and each location, calculations were made to determine the number of hours with $\mathrm{RH}$ $>85 \%$, number of hours with mean air temperature $<5$ to $30^{\circ} \mathrm{C}$ by steps of $5^{\circ} \mathrm{C}$, number of days with precipitation $>0.5$ to $2.5 \mathrm{~mm}$ by steps of $0.5 \mathrm{~mm}$, number of days with precipitation $>5.0$ and $>6.0 \mathrm{~mm}$, the average maximum air temperature, and the accumulated precipitation per year.

The GLM and the ARIMA procedures in the SAS 9.2 software (SAS Institute, Inc.,
Cary, NC) were used to verify the interannual and interregional variations in the weather conditions and to detect trends in daily weather data. A principal component analysis (PCA) using the XLSTAT software (Addinsoft, Paris, France) was used to detect relationships between weather parameters and SBI. The REG procedure and the STEPWISE selection were used to analyze the effects of fruit quality attributes and weather conditions on SBI. These tests were performed in the SAS 9.2 Software (SAS Institute, Inc., Cary, NC).

Modeling of apple phenological development. To introduce a phenological prediction index into the SBI prediction model $\left(\mathrm{SBI}_{\mathrm{dyn}}\right)$, described in the next section, weekly phenological development data from 10 'Honeycrisp' apple trees in the orchards of the experimental farm of Agriculture and Agri-Food Canada in Frelighsburg (QC) were also taken in 2010 and 2011. As for fruit quality analyses, the optimum harvest date for each site was estimated by fruit coloration, a change of background color from green to yellow, and starch index between five and seven, as determined by the Cornell Starch Chart. Weather data from a station located in that orchard were included in the CIPRA software. A base temperature of $5{ }^{\circ} \mathrm{C}$, optimum temperatures between 22 and $25{ }^{\circ} \mathrm{C}$, and a maximum temperature of $36{ }^{\circ} \mathrm{C}$ were used. The apple phenology model is divided into many developmental phases (e.g., budbreak, foliar development, flowering, and fruit development) and predicts daily $\mathrm{BBCH}$ (Biologische Bundesantalt, Bundessortenamt and Chemische Industry) phenological stages (Meier et al., 2001) from budbreak to harvest (Bourgeois et al., 2014a).

Since only full bloom and harvest dates were known for each site and year of data in this study, it was important to link the number of DFB to their related phenological stages using the $\mathrm{BBCH}$ phenological scale. The following asymptotic equation (Eq. [1]) was derived empirically and implemented in TableCurve ${ }^{\circledR}$ 2D 5.01 (SYSTAT Software Inc., CA, 2002) to estimate the parameters that will best fit the $\mathrm{BBCH}$ stages to their equivalent in DFB.

$\mathrm{BBCH}=65+(A-65) *\left(1-\mathrm{e}^{(-B(\mathrm{DFB}-\mathrm{C}))}\right)$

In Eq. [1], parameter $A$ is the maximum value of $\mathrm{BBCH}$, parameter $B$ is the rate of increase of the $\mathrm{BBCH}$ value, and $C$ is a parameter that allows horizontal translocation of the curve. In the case of apples from Frelighsburg in 2010 and 2011, values for the parameters were the following: $A=82.42$, $B=0.015$ (2010) or 0.0165 (2011), and $C=0$, with an $R^{2}$ value of 0.97 for the curve fitting. The resulting $\mathrm{BBCH}$ values corresponded to specific values of DFB as follows: 0 DFB at $\mathrm{BBCH}=65$ (full bloom), $30 \mathrm{DFB}$ at $\mathrm{BBCH}=71$ (fruit size up to $10 \mathrm{~mm}$ ), $60 \mathrm{DFB}$ at $\mathrm{BBCH}=75$ (fruit about $50 \%$ final size), and $90 \mathrm{DFB}$ at $\mathrm{BBCH}=78$ (fruit about $80 \%$ final size).
For each harvest site from 2002 to 2006 and 2009 to 2011, the same asymptotic function was fitted to the two measured $\mathrm{BBCH}$ stages: full bloom (65) and harvest (80). Values of parameter $B$, ranging from 0.0140 to 0.0174 , were obtained by fitting the exact date of harvest for each case.

Modeling susceptibility to soggy breakdown disorder. The percentage of apples affected by soggy breakdown per region was recorded, and hourly weather data from the closest weather stations were selected and implemented in the CIPRA software. The next step was to determine the relationship between specific environmental parameters during the growing season and the occurrence of soggy breakdown to set levels of risks of developing soggy breakdown as the season progressed. Relative weights were assigned to each weather parameter, for each development phase, according to results from the stepwise regression analyses.

The prediction model for $\mathrm{SBI}_{\mathrm{dyn}}$ was based on the following basic equations:

$$
\mathrm{SBI}_{t}=\mathrm{SBI}_{t-1}+\Delta \mathrm{SBI}
$$

$$
\begin{aligned}
\Delta \mathrm{SBI}= & \mathrm{SBI}_{\max } * f(\text { PhenoT }, \text { Temp }) \\
& * f(\text { PhenoP }, \text { Prec })
\end{aligned}
$$

Temperature (Temp) and precipitation (Prec) were initially set to have equivalent relative levels of importance (i.e., 0 to 1 ) in determining the susceptibility to soggy breakdown (Fig. 1B and D). Two functions expressing limits associated with phenology for temperature and precipitation (PhenoT and PhenoP) were included in the model (Fig. 1A and C) because their impact might occur at different phenological stages. Parameter $\mathrm{SBI}_{\max }$ represents the maximum daily increment of SBI that occurs at optimum temperature and precipitation, and $\triangle S B I$ is the daily variation of SBI, depending on weather conditions recorded that day, which is added to the SBI of the previous day $\left(S B I_{t-1}\right)$. A change in SBI from flowering to harvest time is created by this dynamic procedure.

Temperature and precipitation functions were established using thresholds determined from statistical analyses. Precipitation function $[f(P r e c)]$ was divided into two relative weights associated with low or high precipitation levels (Fig. 1D). Temperature function [ $f($ Temp) $]$ was divided into three levels using a linear relation between relative weights and minimum and optimum set temperatures as follows: temperatures between 5 and $20{ }^{\circ} \mathrm{C}$ were associated with decreasing relative weights according to the following equation:

$$
f(\text { Temp })=\left(T_{\text {opt }}-T^{\circ} \mathrm{C}\right) /\left(T_{\text {opt }}-T_{\text {min }}\right)
$$

where $T_{\text {opt }}$ is the optimum temperature of SBI change, and $T_{\min }$ is the minimum temperature of SBI change, which depend on the phase of the growing season, and $T^{\circ} \mathrm{C}$ is the measured temperature (Fig. 1B). 

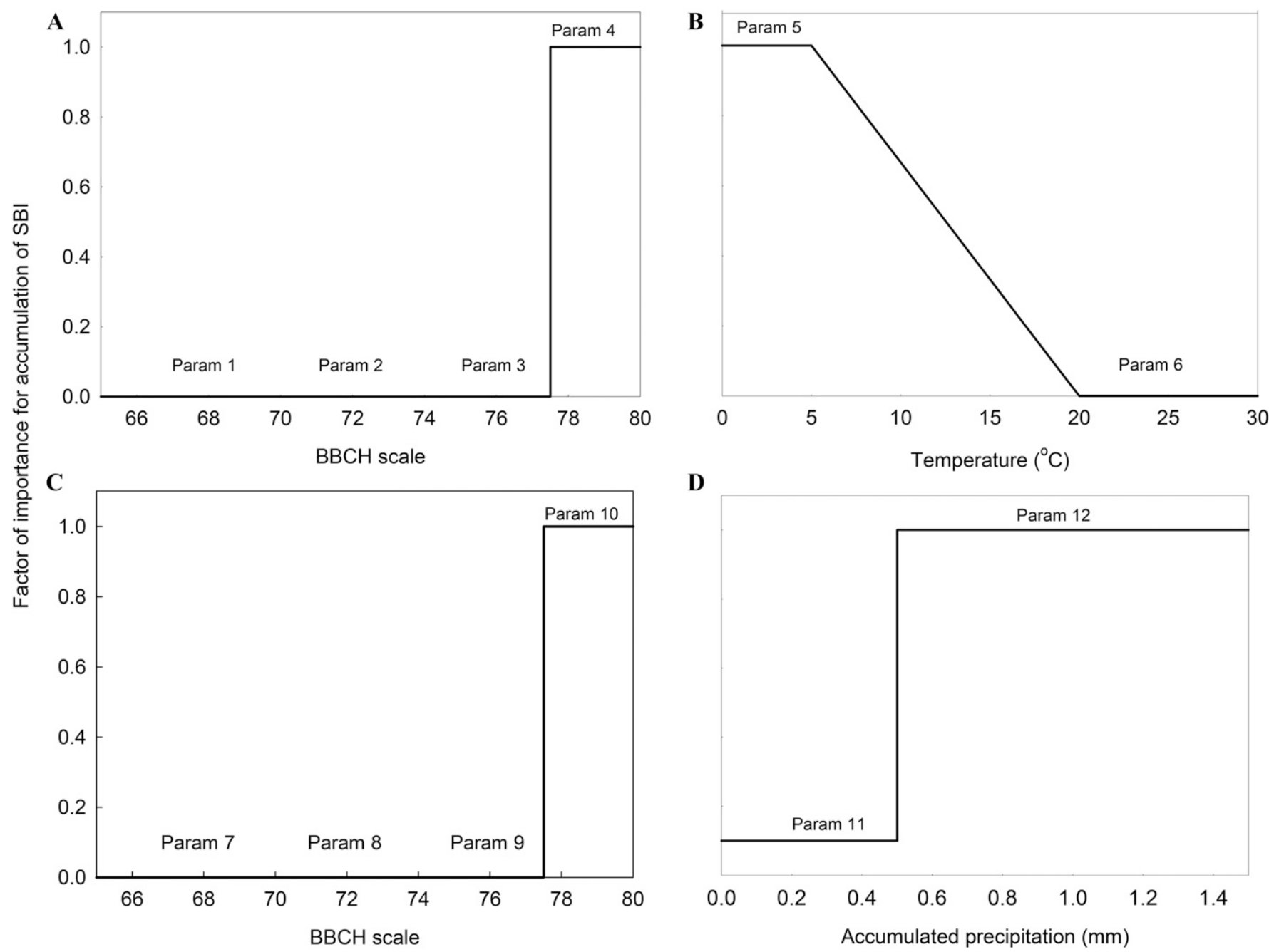

D

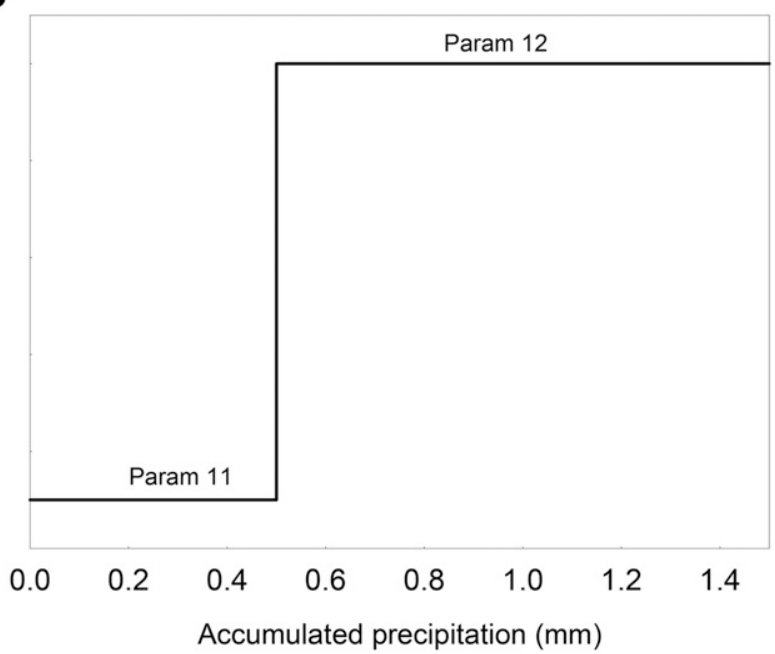

Fig. 1. Relative importance of temperature and precipitation at specific BBCH ("Biologische Bundesantalt, Bundessortenamt and Chemische Industry") phenological stages for soggy breakdown incidence (SBI) during the 'Honeycrisp' apple growing season. (A) As a function of phenological parameter associated with temperature conditions (PhenoT); (B) SBI response to air temperature [f(Temp)]; (C) phenological parameter associated with precipitation conditions (PhenoP); and (D) SBI response to precipitation [f(Prec)].

The $\mathrm{SBI}_{\mathrm{dyn}}$ model was conceptualized and implemented in Visual Basic Application (VBA) in MS Excel software to run with the different weather scenarios over the years and sites and to facilitate the calibration and sensitivity analyses for each parameter described in this section.

Comparisons between predictions from the soggy breakdown model developed in this study and predictions from the $L T D$ riskV2 model developed at Agriculture and Agri-Food Canada (Bourgeois et al., 2014b) using the same sites and years of harvest and weather stations were also conducted.

Calibration and sensitivity analyses for the SBI model. A calibration method was used to determine values for each parameter in the model and to test every combination. Phenological parameters for temperature and precipitation functions were associated with a factor of importance fixed at 1.0 for growth phases that were highlighted in the regressions results (Fig. 1A and C). Outside these phases, parameters were varied from 0 to 0.9 in steps of 0.1 to verify their impact on the prediction of SBI. For the temperature and precipitation functions [f(Temp) and $f$ (Prec)], a factor of importance was fixed at 1.0 for temperature $\leq 5{ }^{\circ} \mathrm{C}$ (Fig. $\left.1 \mathrm{~B}\right)$, the lower threshold temperature for development of apple trees, and accumulated precipitation $>0.5 \mathrm{~mm}$ (Fig. 1D). For each combination of values assigned to each parameter tested, the $\mathrm{SBI}_{\max }$ value was adjusted to obtain the exact mean value of SBI for all regions and years.

To compare accuracies of predicted SBI between combinations, the following statistical criteria were used: root mean square error (RMSE), which provides a measure of the magnitude of the difference; forecasting efficiency $(\mathrm{EF})$, which gave a measure of the goodness of fit; and mean error (E), which presents a measure of the direction of the difference (Yang et al., 2000). Good predictions will have values as follows: RMSE close to zero, EF close to one, and E close to zero. The percentage of well-estimated ( $\pm 5 \%$ of observed SBI), overestimated, and underestimated cases of SBI was also calculated.
Sensitivity analyses were also conducted on each parameter that was fixed to a relative weight below 1.0, as shown in Fig. 1 (Param $1,2,3,6,7,8,9$, and 11), maintaining all other parameters constant. The first goal of sensitivity analyses was to test the sensitivity of the mean value of the estimated SBI, for each site and year of harvest, to variations in parameters. This test indicates which parameters are more sensitive; hence, have a higher importance for their precision to predict accurate SBI, considering that parameters fixed at higher factor of importance (relative weight $=1$ ) are truly the most important because sensitivity analyses were not conducted on them.

\section{Results and Discussion}

Fruit quality attributes. Fruit quality analyses at harvest are indicators of apple maturity and help set marketing strategies because of their impact on storage life. Apples in this study had fairly constant values of diameters $(7.6-8.9 \mathrm{~cm})$, firmness $(56.9-80.2 \mathrm{~N})$, and malic acid content (536-771 mg per 
$100-\mathrm{mL}$ of juice). There were large variations in blush (46.0\% to $91.1 \%)$, internal ethylene concentration ( 0.1 to $70.7 \mathrm{ppm})$, starch index (5.1 to 8.5$)$, and soluble solids content (11.7\% to $14.4 \%$ ) (Table 1$)$.

The only parameter that varied significantly during storage was titratable acidity, the malic acid content, which has a logarithmic decline in relation with fruit development (Zhang et al., 2010). A regression analysis on the effect of fruit quality attributes either at harvest or after storage on the incidence of soggy breakdown showed that no relationship existed. The combined effects of these attributes at harvest with weather conditions during the growing season on the incidence of soggy breakdown are discussed in the section on regression analyses. The incidence of soggy breakdown ranged from $0 \%$ to $37 \%$ within the data set (Table 1).
Interregional and interannual weather analyses. Over all years combined, the sites of Newcastle (ON), Kentville (NS), Norfolk Co. (ON), and Île d'Orléans (QC) and the years of harvest 2009 to 2011 were significantly different from the other sites and years of harvest included in this study. Precipitation conditions between these locations were significantly different for most comparisons, and temperature conditions were significantly different mostly for Kentville and Île d'Orléans with lower temperature recorded from 91 DFB until harvest compared with the other sites in this study. The years from 2009 to 2011 had different precipitation and temperature conditions than the other years of harvest in this study. In 2010 and 2011, higher occurrences of days with precipitation were recorded over the phase of 31 DFB until harvest, and in 2009, the phase from 91 DFB until harvest recorded a greater number of hours of low temperature.

Principal component analyses. Based on the results of the PCA, correlated weather parameters were aggregated. The parameters of maximum average temperature were aggregated together because values for all phases associated with DFB varied in the same direction according to the factorial axes of the circle of correlations. From the PCA test, significant correlations were detected between SBI and the number of hours when mean air temperatures were $<5,<10,<15$, and $<20{ }^{\circ} \mathrm{C}$ from 91 DFB until harvest (respectively, $r=0.598,0.499,0.492$, and 0.481 , for all $P<0.05$ ).

Regressions with weather data as explanatory variables for soggy breakdown. Three weather variables were identified by the stepwise regression analysis, explaining a significant variability in SBI from the sites

Table 1. Fruit quality analyses of 'Honeycrisp' apples from Ontario, Quebec, and Nova Scotia (Canada) at harvest and soggy breakdown incidence after 3 to 4 mo. in air storage at $3{ }^{\circ} \mathrm{C}$ (years 2002 to 2006 ) and after 4 to 5 mo. at $0.5-1.0^{\circ} \mathrm{C}$ (years 2009 to 2011 ).

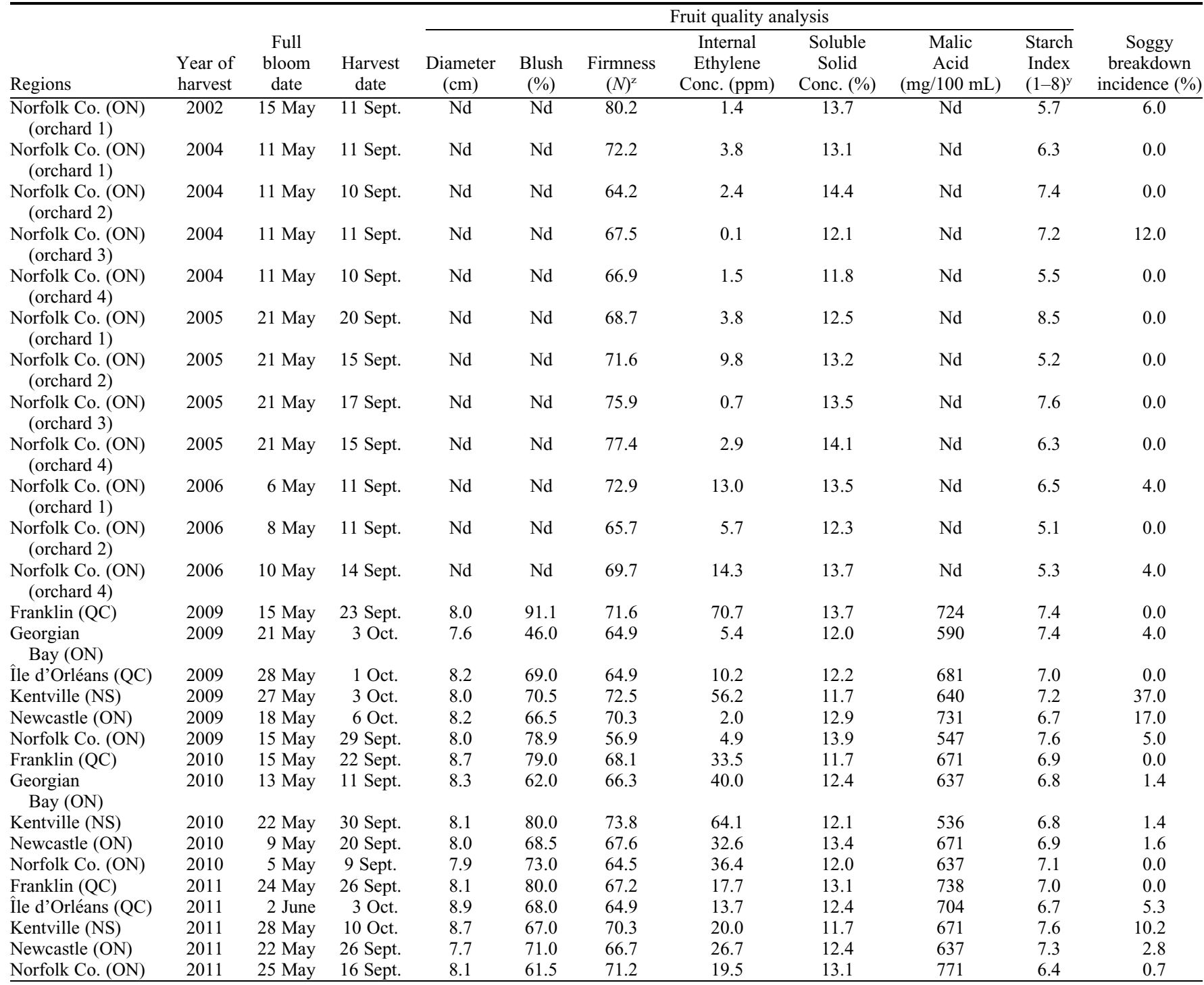

$\mathrm{Nd}=$ not determined.

${ }^{\mathrm{z}}$ Firmness values are the average of two sides.

${ }^{\mathrm{y}}$ According to the Cornell University generic starch-iodine index chart for apples. 
and years (Table 2). The selected regression model for soggy breakdown incidence regression model $\left(\mathrm{SBI}_{\text {reg }}\right)$ was:

$$
\begin{aligned}
\mathrm{SBI}= & -4.25+0.07 \text { Prec }_{91} \mathrm{DFB}-H \\
& +0.44\left(T^{\circ} \mathrm{C}<5\right)_{91 D F B-H}
\end{aligned}
$$

$\left(R^{2}=0.4820 ; P=0.0003\right)$, where Prec $_{91}$ DFB-H is the accumulated precipitation from 91 DFB until harvest and $\left(T^{\circ} \mathrm{C}<5\right)_{91} D F B-H$ is the number of hours when mean air temperature is $<5{ }^{\circ} \mathrm{C}$ from $91 \mathrm{DFB}$ until harvest. The estimation of $\mathrm{SBI}$ values with the $\mathrm{SBI}_{\text {reg }}$ model including only weather conditions during the growing season is considered adequate, with $71 \%$ of the predictions located in the threshold of $\pm 5 \%$ of the observed $\mathrm{SBI}(\mathrm{RMSE}=5.46, \mathrm{EF}=0.48$, and $E=-0.46)$.

Precipitation during the 91 DFB until harvest accounted for $12.5 \%$ of variation in SBI, whereas its values varied from 26.2 to $193.0 \mathrm{~mm}$ of accumulated precipitation for all the sites and years. The positive relationship between accumulated precipitation, low temperature between 91 DFB until harvest, and SBI implied a greater incidence in years with lower temperatures and more precipitation more or less 1 month before harvest. Low temperature during this last phase before harvest accounted for $36 \%$ of the variability in SBI between all the sites and years. During 91 DFB until harvest, 0 to $40 \mathrm{~h}$ below $5^{\circ} \mathrm{C}$ occurred.

Temperature and precipitation during the phase of fruit development just before harvest were related to the susceptibility of 'Honeycrisp' apples to soggy breakdown development later in storage. The phase of 3 to 4 weeks before harvest (BBCH stages 78 to 80 ) represents the most important month of the growing season, just before the climacteric rise of apples. According to the data set on phenological development of 'Honeycrisp' apples in 2010 and 2011, between BBCH stages 78 and 80, diameter varies between 67 and $88 \mathrm{~mm}$, which represent $80 \%$ to $100 \%$ of the total final diameter.

Most of the SBI variability (47\%) is explained by the two parameters in the $\mathrm{SBI}_{\text {reg }}$ model (Eq. [5]): higher precipitation and lower temperature conditions 1 month before harvest. Accumulated precipitation varied substantially in some cases, with more than $150 \mathrm{~mm}$ of rainfall in 3 to 4 weeks. This weather parameter is known to be linked negatively with solar radiation, leading to less solar radiation when accumulated precipitation is high. This may include the effect of shading, which is known to increase the susceptibility to internal browning (Bramlage, 1993). Low light intensity is known to reduce anthocyanin, carbohydrates, acid contents, and ascorbic acid content, which is an oxidative browning inhibitor of apples (Albrigo and Childers, 1970). High precipitation for apple trees may also cause low oxygen stress in the root system.

High precipitation implies high water availability for the apple tree. In combination with cooler temperature, which decreases the rate of transpiration in apples (Snowdon, 1990), these conditions may have an impact on the interaction between fruit growth, water relations, and nutrient transport. Studies on preharvest factors affecting physiological disorders of fruit have hypothesized that these interactions may determine the susceptibility of apples to disorders (Ebel et al., 1993; Ferguson et al., 1999).

In the current literature, causes for internal browning are hypothesized based on chilling injury studies, whose symptoms resemble this disorder, or studies directly related to cellular dysfunction. Meheriuk et al. (1994) suggested that the immediate cause of internal tissue browning is the failure of cell membranes in retaining the phenolic precursors of browning within the vacuole. Knowledge of the factors provoking this membrane failure that led to cell disorganization is still not completely understood. Whether it is a biological, chemical, or environmental stress induced in late season, they all have been suspected to initiate or delay the onset of ethylene climacteric rise, affecting the potential storage life of apples (Dilley and Dilley, 1985).

Regressions with weather and fruit quality data as explanatory variables for soggy breakdown. When considering the effect of fruit quality attributes in conjunction with weather from the growing season, different regressions result from stepwise re- gression analyses (Table 2). For SBI, the final model was:

$$
\begin{aligned}
\mathrm{SBI}= & -38.22+0.47 \text { Firmness } \\
& +0.09 \text { Prec }_{91} \text { DFB }-H \\
& +0.48\left(T^{\circ} \mathrm{C}<5\right)_{91} \text { DFB-H } \\
& +0.15\left(T^{\circ} \mathrm{C}<10\right)_{31-60 D F B} \\
& -0.89(\text { daysprec }>6.0)_{0-30 D F B}
\end{aligned}
$$

$\left(R^{2}=0.6558 ; P \leq 0.0001\right)$, where Firmness is the measured fruit firmness at harvest, $\left(T^{\circ} \mathrm{C}<\right.$ $10)_{31-60 ~ D F B}$ is the number of hours when mean air temperature is $<10^{\circ} \mathrm{C}$ from 31 to 60 $\mathrm{DFB}$, and (daysprec $>6.0)_{0-30} \mathrm{DFB}$ is the number of days when accumulated precipitation is $>6.0 \mathrm{~mm}$ from 0 to $30 \mathrm{DFB}$. Other weather variables are already defined in Eq. [5]. The estimation of SBI values with the regression equation, including both fruit quality attributes at harvest and weather conditions during the growing season, is considered adequate with $75 \%$ of the predictions that are located in the threshold of $\pm 5 \%$ of the observed SBI $(\mathrm{RMSE}=4.33, \mathrm{EF}=0.67$, and $E=-0.48$ ).

The main differences from the regression analyses considering only weather conditions on soggy breakdown susceptibility are the implication of fruit firmness at harvest, low temperatures from 31 to $60 \mathrm{DFB}$, and precipitation from 0 to $30 \mathrm{DFB}$, with a positive relationship between fruit firmness at harvest and soggy breakdown susceptibility (Ehsani and DeEll, 2013). Firmness varied between 56.9 and $80.2 \mathrm{~N}$ over all sites and years of harvest and accounted for only $7 \%$ of the variability in SBI. Precipitation and low temperature in the phase from 91 DFB until harvest accounted for $12 \%$ and $36 \%$ of variability of SBI, respectively. These values were similar to regressions, including only weather condition effects during the entire growing season. There was a greater SBI in the years and sites with more precipitation and lower temperature at least 1 month before harvest. Number of hours $<10{ }^{\circ} \mathrm{C}$ from 31 to 60 DFB varied between 0 and $42 \mathrm{~h}$ and accounted for only $5 \%$ of the SBI variability for all sites and years of harvest. Its positive

\begin{tabular}{|c|c|c|c|}
\hline Variable & Phase of fruit development (DFB) & Parameter estimate & Partial $R^{2}$ \\
\hline Accumulated precipitation & 91 DFB until harvest & $0.07 *$ & 0.1245 \\
\hline Number of hours when mean air temperature $<5^{\circ} \mathrm{C}$ & 91 DFB until harvest & $0.44 * * *$ & 0.3575 \\
\hline \multicolumn{4}{|c|}{ Weather conditions combined with fruit quality at harvest effect } \\
\hline Intercept & - & $-38.22 *$ & - \\
\hline Firmness & - & $0.47 *$ & 0.0715 \\
\hline Number of days when accumulated precipitation $>6.0 \mathrm{~mm}$ & $0-30$ & $-0.89^{\mathrm{NS}}$ & 0.0564 \\
\hline Number of hours when mean air temperature $<5{ }^{\circ} \mathrm{C}$ & 91 DFB until harvest & $0.48 * * *$ & 0.3575 \\
\hline
\end{tabular}
relationship with the susceptibility level of soggy breakdown indicated a greater incidence in sites and years with lower temperatures during 31 to 60 DFB. Number of

Table 2. Multiple linear regression of the weather conditions effect, alone and combined with fruit quality at harvest, on soggy breakdown incidence for specific phases of fruit development (days from full bloom, DFB) for all sites and years in this study.

NS, *, **, ***Nonsignificant or significant at $P \leq 0.05,0.01$, or 0.001 , respectively. 
days when accumulated precipitation was $>6.0 \mathrm{~mm}$ from 0 to $30 \mathrm{DFB}$ varied between 0 and $7 \mathrm{~d}$ and accounted for only $6 \%$ of the SBI variability in the observations. The negative relationship between this parameter and soggy breakdown susceptibility indicated a greater incidence in sites and years with lower precipitation occurrences during that phase of the growing season. Fruit quality attributes at harvest were tested for their effect alone on SBI, but no parameter came out significant at $P<0.05$.

Fruit quality attributes revealed a positive effect of firmness at harvest on soggy breakdown susceptibility (Table 2), implying a higher incidence when fruit are more firm at harvest. This texture criterion is one of the most important qualities that 'Honeycrisp' apples maintain during long periods of storage (Nichols et al., 2008). However, this quality attribute may lead to higher susceptibility to soggy breakdown. Its apple peel is particularly thin and could be punctured easily by other stems of apples during harvesting and transport (DeEll, 2005). Greasiness level, which increases with high maturity at harvest, has been associated with the changes in wax and oil composition of the skin (Morice and Shorland, 1973) and is known to be high in 'Honeycrisp' apples (Watkins et al., 2005). These factors combined may limit the exchange of gas between the atmosphere and the fruit, leading to anaerobic conditions and development of fermentation products. This kind of development has been seen in late-harvested apples of this cultivar (DeEll, 2005), although no relationship with SBI has been reported. The fact that no single fruit quality attribute revealed an effect on SBI supports the concept that the overall interaction with weather conditions during the growing season may account for the soggy breakdown susceptibility.

Calibration of the $S B I_{d y n}$ model. From the results with only the effect of weather conditions on SBI (Eq. [5]), 12 parameters for the model were established as in Fig. 1 and Table 3. According to the regression (Eq. [5]), a higher importance was given to high precipitation and low temperature from 91 DFB until harvest (BBCH 78 to 80). Lower and upper limits for temperature and pre- cipitation were fixed at temperatures $<5{ }^{\circ} \mathrm{C}$ and $>0.5 \mathrm{~mm}$ of accumulated precipitation (Fig. 1B and D) based on the lower threshold temperature for the development of apple trees (Landsberg, 1974) and on the minimum threshold for significant accumulated precipitation due to the rain gauge precision (Environment Canada, 2004). For temperatures between 5 and $20^{\circ} \mathrm{C}$, relative weight parameters were considered to decrease linearly at a rate that depended on the relative weight assigned to temperature above $20{ }^{\circ} \mathrm{C}$ (Fig. 1B).

The low values of SBI and overall nonnormal distribution of the observed incidence values were important factors to consider in the overall accuracy of the $\mathrm{SBI}_{\mathrm{dyn}}$ model. Since the model was built based on data with mostly low incidences of soggy breakdown, it is normal that predictions are best in cases of low susceptibility.

Between observed values and predictions from both $\mathrm{SBI}_{\mathrm{dyn}}$ and $\mathrm{SBI}_{\text {reg }}$ models, important variations in their capacities to predict more or less extreme values of SBI are observed (Fig. 2). SE associated with each are $7.7 \%, 4.1 \%$, and $5.3 \%$, respectively. As an example, the daily and accumulated SBI during the growing season were illustrated, using the predictions from the $\mathrm{SBI}_{\text {dyn }}$ model, for the sites of Kentville, Newcastle and Norfolk Co. in 2009, Simcoe in 2006, Georgian Bay in 2010, and Norfolk Co. in 2011 (Fig. 3).

The purpose of the $\mathrm{SBI}_{\mathrm{dyn}}$ model is to predict daily levels of susceptibility to the disorder during the entire growing season, to indicate variations of risk index, and to supply a final risk index of SBI to 'Honeycrisp' apple producers at harvest time. Therefore, it is appropriate to use multiplicative effects integrated in a dynamic model.

A principal component analysis on the effect of number of hours when temperature is $<5{ }^{\circ} \mathrm{C}$ showed a greater importance than lower temperature thresholds for the entire growing season. For the phase of 91 DFB until harvest, all numbers of hours when temperature is $<5,10,15$, and $20^{\circ} \mathrm{C}$ revealed significant $(P<0.05)$ positive correlations with the incidences of soggy breakdown observed in all cases.

A principal component analysis was also conducted on the effect of the number of days with accumulated precipitation $>0.5$ to $6.0 \mathrm{~mm}$ by steps of $0.5 \mathrm{~mm}$ on soggy breakdown susceptibility. There was a positive but nonsignificant $(r=0.372, P>0.05)$ correlation between the accumulated precipitation from BBCH 78 to 80 and SBI.

A gradual increase in the relative weight associated with the precipitation function as the values increase from minimum to maximum thresholds, as in the function of temperature (Fig. 1B), would probably lean toward more accurate predictions of SBI. However, since the high precipitation effect is combined with low-temperature conditions to increase soggy breakdown susceptibility, it is difficult to determine the maximum threshold for high precipitation effect. The apples harvested in Kentville (NS) in 2009, which recorded the highest SBI (37\%), had the second highest accumulated precipitation $(161 \mathrm{~mm})$ and number of hours $<5{ }^{\circ} \mathrm{C}(30$ h) for $\mathrm{BBCH}$ stages from 78 to 80 . However, Franklin in 2011, which had the highest accumulated precipitation $(193 \mathrm{~mm})$ and recorded 1 hour $<5{ }^{\circ} \mathrm{C}$ during the same developmental phase, showed $0 \%$ SBI. On a different perspective, the case that accumulated the most number of hours $<5^{\circ} \mathrm{C}$, which was Kentville in 2011 with $40 \mathrm{~h}$, also recorded a low amount of precipitation, $33.4 \mathrm{~mm}$ between BBCH 78 and 80 , showed $10.2 \%$ SBI. This supports the higher importance to be assigned to lower temperature when modeling soggy breakdown susceptibility in 'Honeycrisp' apples.

The change in daily SBI followed some pattern for each case, as shown in Fig. 3, where the curves of accumulated SBI were results of higher slopes between $\mathrm{BBCH}$ stages 78 to 80 . In the case of Kentville in 2009 , predicted by the $\mathrm{SBI}_{\mathrm{dyn}}$ model, the slope of the curve from $\mathrm{BBCH} 78$ to 80 was almost twice the slope of the Norfolk Co. in 2009 curve for the phase of the growing season. For Newcastle in 2009, SBI became higher than that of Norfolk in 2009, due to $3 \mathrm{~d}$ of lower temperature and higher precipitation accumulation conditions preceding harvest time. As for the three other cases illustrated in Fig. 3, they maintained the lowest slopes of SBI during $\mathrm{BBCH}$ stages 78 to 80 because there were lower occurrences of both low temperature and high precipitation during this phase.

Table 3. Description and values of parameters of the soggy breakdown incidence (SBI) model, including the factor of correction for amplitude of the model $\left(\mathrm{SBI}_{\max }\right)$, factors of importance for each phenological phase associated with the temperature and precipitation submodels (PhenoT and PhenoP), factors of importance associated to variations of temperature or accumulated precipitation $[f($ Temp $)$ and $f(P r e c)]$, and results of the selected sensitivity analyses.

\begin{tabular}{|c|c|c|c|c|c|c|}
\hline Phenological phase & $\begin{array}{l}\text { Weather } \\
\text { parameter }\end{array}$ & $\begin{array}{l}\text { Parameter } \\
\text { code }\end{array}$ & $\begin{array}{c}\text { Weather } \\
\text { conditions range }\end{array}$ & $\begin{array}{l}\text { Parameter number } \\
\quad \text { (see Fig. 1) }\end{array}$ & $\begin{array}{l}\text { Value of each parameter } \\
\text { in scenario } 1^{\mathrm{z}}\end{array}$ & $\begin{array}{c}\text { Variation in } \\
\text { mean SBI }(\%)^{y}\end{array}$ \\
\hline \multirow{5}{*}{$78<$ BBCH scale $\leq 80$} & \multirow{2}{*}{ Temperature } & Phenot & - & 4 & 1 & - \\
\hline & & $f($ Temp $)$ & Temperature $\leq 5{ }^{\circ} \mathrm{C}$ & 5 & 1 & - \\
\hline & \multirow[t]{3}{*}{ Precipitation } & PhenoP & - & 10 & 1 & - \\
\hline & & f(Prec) & Precipitation $\leq 0.5 \mathrm{~mm}$ & 11 & 0.1 & 20.7 \\
\hline & & & Precipitation $>0.5 \mathrm{~mm}$ & 12 & 1 & - \\
\hline
\end{tabular}

${ }^{\mathrm{z}}$ Root mean square error $(\mathrm{RMSE})=6.45$, efficiency $(\mathrm{EF})=0.28$, mean error $(E)=-0.04,14 \%$ overestimated cases, $18 \%$ underestimated cases, $68 \%$ well-estimated cases (at threshold of $\pm 5 \%$ ).

${ }^{\mathrm{y}}$ Using a variation of \pm 0.1 for the parameter values tested in scenario 1 . 


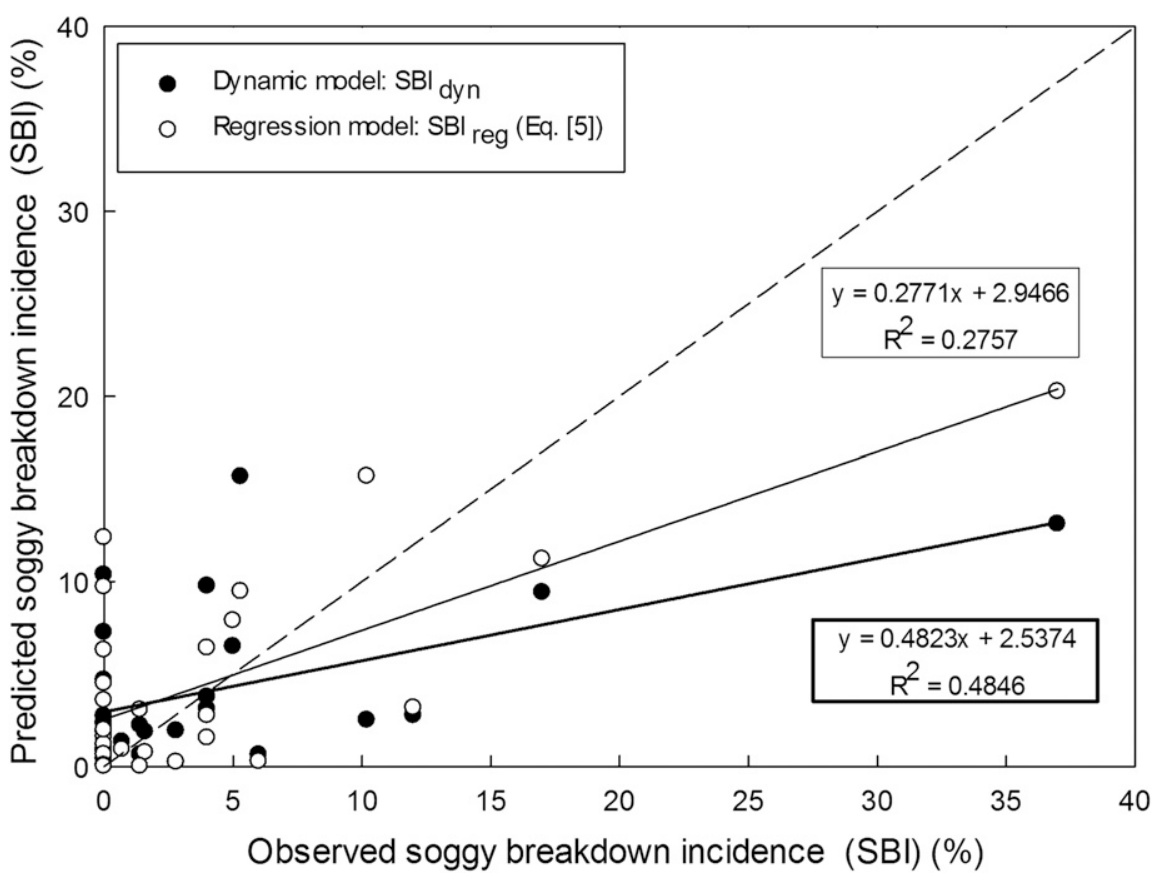

Fig. 2. Predicted soggy breakdown incidence (SBI) (\%) from either the regression in Eq. [5] or predictions from the SBI model as a function of observed SBIs for all sites and years included in this study, with their corresponding tendency curves for the $\mathrm{SBI}_{\text {reg }}$ and $\mathrm{SBI}_{\mathrm{dyn}}$ models.

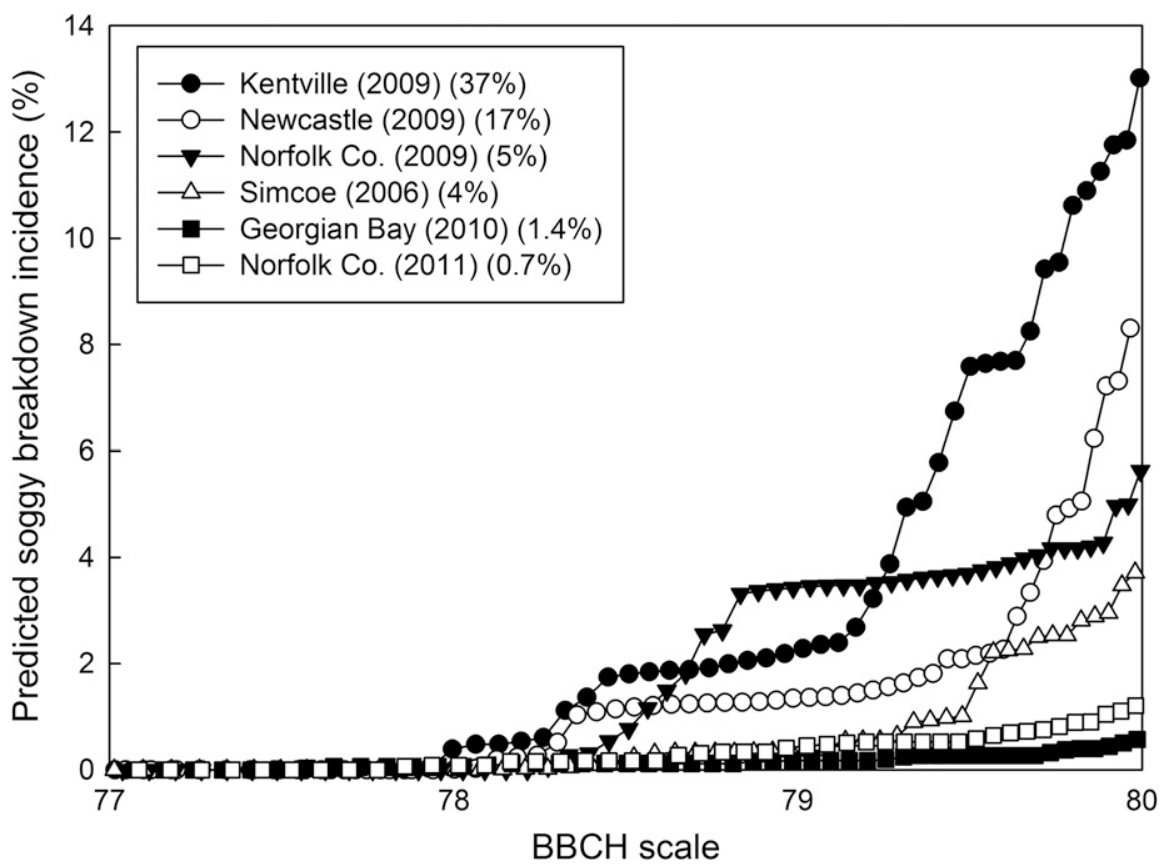

Fig. 3. Soggy breakdown incidence (SBI) in 'Honeycrisp' apples during the last part of the growing season according to the phenological BBCH scale, for six sites and years of harvest, predicted with the $\mathrm{SBI}_{\mathrm{dyn}}$ model. The observed SBI at harvest is indicated in parenthesis for each site and year of harvest.

Over this phase of $\pm 45 \mathrm{~d}$, the sites of Kentville, Newcastle, and Norfolk in 2009 accumulated the most precipitation, with 161,158 , and $123 \mathrm{~mm}$, respectively, and recorded the highest number of hours with mean air temperature $<10^{\circ} \mathrm{C}$, with 195,152 , and $97 \mathrm{~h}$, respectively. This combination of weather conditions is what led to the highest SBI observed. As for the cases of Simcoe in 2006, Georgian Bay in 2010, and Norfolk in on soggy breakdown used in this study provided a wider range of incidences predicted $(\mathrm{SE}=13.9 \%)$ compared with the $\mathrm{SBI}_{\mathrm{dyn}}$ model, although the mean of all predicted incidences was very high $($ mean $=13.5 \%)$ compared with observed values and with predictions from the $\mathrm{SBI}_{\mathrm{dyn}}$ model. The overall predictions with the LTD-riskV2 resulted in $42.9 \%$ of well estimated cases, within $\pm 5 \%$ of the observed SBI, included in this study. This was actually lower than predictions from the $\mathrm{SBI}_{\text {dyn }}$ model $(67.9 \%)$ as well as lower than the $\mathrm{SBI}_{\text {reg }}$ model (71.4\%). Predictions from the LTD-riskV2 model (Bourgeois et al., 2014b) supported that 'Honeycrisp' apples react either to different weather conditions or different weights associated with these weather conditions of temperature and solar radiation, which were highly correlated with the number of days with precipitation.

Just as the LTD-riskV2 model, the $\mathrm{SBI}_{\mathrm{dyn}}$ model was not able to provide good predictions for all cases of SBI. Although, when considering that preharvest weather conditions alone represented $48.0 \%$ of the variability in SBI, this initial $\mathrm{SBI}_{\mathrm{dyn}}$ model, with an accuracy of $67.9 \%$, is regarded as a good start for the prediction of soggy breakdown applied to multiple weather conditions.

Sensitivity analyses of the $S B I_{d y n}$ model. For the parameters PhenoT from BBCH 65 to 78 (Parameters 1, 2, and 3, Fig. 1A) and PhenoP from BBCH 65 to 78 (Parameters 7, 8 , and 9 , Fig. 1C), the relative weights were fixed at zero and no sensitivity analyses were conducted on them.

Parameters 6 and 11 from the $\mathrm{SBI}_{\mathrm{dyn}}$ model (Fig. 1B and D) were varied independently and tested for their effect on the mean of predicted SBI. Variations of relative weight from 0 to 0.1 for the parameter $6\left(f(\right.$ Temp $\left.) \geq 20{ }^{\circ} \mathrm{C}\right)$ and from 0.1 to either 0 or 0.2 for parameter 11 $[f$ (Prec) $<0.5 \mathrm{~mm}]$ resulted in an increase of 63 and $21 \%$, respectively, in variations from the mean-predicted SBI from the $\mathrm{SBI}_{\mathrm{dyn}}$ model, with all sites and years of harvest confounded (Table 3 ). These two parameters are sensitive and require greater precision to improve the accuracy of the SBI model, assuming that parameters set at relative weights of 1.0 are truly the most important in predicting SBI after harvest because of the change in susceptibility level indices during the growing season.

Variations in the daily accumulated SBI when parameter 6 was at relative weights 0 or 0.1 showed similar slopes in the overall curve, with a difference for the accumulated SBI during BBCH stages 78 to 80 (Table 3 ). It was normal to detect a high level of sensitivity for the parameter of $f$ (Temp) when temperature was $\geq 20{ }^{\circ} \mathrm{C}$ since it affected all relative weights associated with temperature conditions $>5{ }^{\circ} \mathrm{C}$ also due to its linear decrease between these two temperatures (Fig. 1B). The variation of relative weight from 0 to 0.1 for this parameter altered the effect of temperature at the end of the growing season, when temperature conditions between 5 and $20{ }^{\circ} \mathrm{C}$ were more 
frequent. The PhenoT parameter fixed at relative weight value of 1.0 also explained the high increase in the slope for the accumulated SBI during the BBCH stages 78 to 80 when $f$ (Temp) for temperature $\geq 20^{\circ} \mathrm{C}$ had a relative weight increased to 0.1 .

The variation of relative weight associated with $f(P r e c)$ when precipitation was $<0.5 \mathrm{~mm}$ from 0.1 to either 0 or 0.2 also revealed a high level of sensitivity for that parameter on mean SBI predicted by $\mathrm{SBI}_{\text {dyn }}$ (Table 3). The transfer from relative weight 0.1 to 0 implied that there was no SBI change $<0.5 \mathrm{~mm}$, decreasing importantly the overall SBI change from BBCH stages 78 to 80 . The transfer from 0.1 to 0.2 amplified the effect of precipitation conditions $<0.5 \mathrm{~mm}$ at a level that depended on the occurrence of low daily accumulated precipitation during this phase. It was important to consider that the use of relative weights 0.1 or 0.2 implied a change in soggy breakdown susceptibility level even when there was no daily precipitation accumulated (Fig. 1D). Therefore, the multiplied effects of temperature and precipitation responses would determine the overall daily $\triangle S B I$ from $\mathrm{BBCH}$ stages 78 to 80 .

\section{Conclusions}

Prediction of SBI in 'Honeycrisp' apples had not been attempted until now. The $\mathrm{SBI}_{\mathrm{dyn}}$ model provides a risk level to soggy breakdown at harvest by accumulating SBI values (\%) using weather conditions mainly during the BBCH stages 78 to 80 (91 DFB until harvest). Additional evaluations of the $\mathrm{SBI}_{\mathrm{dyn}}$ model using sets of data from the same sites for future years of harvest need to be conducted for improvement of the accuracy level of this initial model. Results from this study suggest that high firmness could increase the susceptibility level of soggy breakdown in this cultivar. Decrease in malic acid content was the only significant difference between fruit at harvest and after 3 months in storage, with no effect established on the incidence of soggy breakdown.

The long-term applicability of this proposed model is to determine what temporal and spatial conditions are required to reduce or remove completely the susceptibility for soggy breakdown in 'Honeycrisp' apples. Studies of apples preharvest fruit maturity development would be considered helpful in the interpretation of the preharvest weather conditions effect on different disorders susceptibility. Also, to maximize storage duration, it would be complementary to analyze more closely the development of these disorders during storage, as combined with predictions of susceptibility levels. This would permit producers to store apples for short term even in high susceptibility years, by removing the apples before soggy breakdown has developed.

\section{Literature Cited}

Albrigo, L.G. and N.F. Childers. 1970. Peel flavonols and their relationship to superficial scald in 'Stayman' apples. J. Amer. Soc. Hort. Sci. 95:798-800.

Blanpied, G.D. and K.J. Silsby. 1992. Predicting harvest date windows for apples. Cornell $\mathrm{Co}-$ operative Extension, Ithaca, NY.

Bourgeois, G., D. Plouffe, N. Beaudry, D. Choquette, G. Chouinard, and S. Bellerose. 2014a. Using the DJPheno software for model calibration and validation of apple phenological stages. Proc. of the IXth Intl. Symp. on Modelling in Fruit Research and Orchard Management. Acta Hort. 1068:117-123.

Bourgeois, G., D. Plouffe, J. DeEll, and C. Pitiot. 2014b. Evaluation of a pre-harvest bioclimatic model for predicting the risk of low temperature disorders of stored apples in Canada and France. Proc. of the IXth Intl. Symp. on Modelling in Fruit Research and Orchard Management. Acta Hort. 1068:243-251.

Bramlage, W.J. 1993. Interactions of orchard factors and mineral nutrition on quality of pome fruit. Acta Hort. 326:15-28.

DeEll, J.R. 2005. Postharvest quality of 'Honeycrisp' apples. Proc. of the 21st Annual Tree Fruit Postharvest Conf., In conjunction with the 101st Annual Washington State Horticultural Association Mtg., 162-163.

DeEll, J.R. and B. Ehsani-Moghaddam. 2010. Preharvest 1-methylcyclopropene treatment reduces soft scald in 'Honeycrisp' apples during storage. HortScience 453:414-417.

Dilley, C.L. and D.R. Dilley. 1985. New technology for analysing ethylene and determining the onset of the ethylene climacteric of apples. In: S.M. Blankenship (ed.) Controlled atmospheres for storage and transport of perishable commodities. Proc. of the 4th National Controlled Atmosphere Research Conf. N.C. State Univ. Hort. Rpt., 353-362.

Ebel, R.C., E.L. Proebsting, and M.E. Patterson. 1993. Regulated deficit irrigation may alter apple maturity, quality, and storage life. HortScience 282:141-143.

Ehsani-Moghaddam, B. and J.R. DeEll. 2013. Relationships among postharvest ripening attributes and storage disorders in 'Honeycrisp' apple. Fruits 68:323-332.

Environment Canada. 2004. MSC guidelines for co-operative climatological autostations. Meteorological Service of Canada, Atmospheric Environment Service, Downsview, ON, Canada.

Environment Canada. 2010. National climate data and information archive. 1 Mar. 2010. <http:// www.climate.weatheroffice.gc.ca>.

Ferguson, I., R. Volz, and A. Woolf. 1999. Preharvest factors affecting physiological disor- ders of fruit. Postharvest Biol. Technol. 153:255-262.

Lachapelle, M., G. Bourgeois, J. DeEll, K.A. Stewart, and P. Séguin. 2013. Modeling the effect of preharvest weather conditions on the incidence of soft scald in 'Honeycrisp' apples. Postharvest Biol. Technol. 85:57-66.

Landsberg, J.J. 1974. Apple fruit bud development and growth; Analysis and an empirical model. Ann. Bot. (Lond.) 385:1013-1023.

Meheriuk, M., R.K. Prange, P.D. Lidster, and S.W Porritt. 1994. Postharvest Disorders of Apples and Pears. Agriculture and Agri-Food Canada. Agr. Can. Publ. 1737/E, Ottawa.

Meier, U., H. Bleiholder, E. Weber, C. Feller, M. Hess, H. Wicke, T. van den Boom, P.D. Lancashire, L. Buhr, H. Hack, R. Klose, and R. Stauss. 2001. Growth stages of mono-and dicotyledonous plants; $\mathrm{BBCH}$ Monogr.

Moran, R.E., J.R. DeEll, and W. Halteman. 2009. Effects of preharvest precipitation, air temperature, and humidity on the occurrence of soft scald in Honeycrisp apples. HortScience 446:1645-1647.

Morice, I.M. and F.B. Shorland. 1973. Composition of the surface waxes of apple fruits and changes during storage. J. Sci. Food Agr. 2411:1331-1339.

Nichols, D., J. Hebb, P. Harrison, R. Prange, and J. DeLong. 2008. Atlantic Canada - 'Honeycrisp': Harvest, conditioning and storage. AAFC Atlantic Food and Horticulture Research Centre, FactSheet, Kentville, Canada.

Plagge, H.H. and T.J. Maney. 1928. Soggy Breakdown of apples and its control by storage temperature. Res. Bul. Iowa Agricultural Expt. Station 115

Sarrazin, D. 2006. Diagnostic du Réseau Pommier. Centre d'études nordiques, Université Laval.

Snowdon, A.L. 1990. A Colour atlas of postharvest diseases \& disorders of fruits \& vegetables. Vol. 1: General introduction \& fruits. Wolfe Scientific, London.

Wargo, J.M. and C.B. Watkins. 2004. Maturity and storage quality of 'Honeycrisp' apples. HortTechnology 144:496-499.

Watkins, C.B., M. Erkan, J.F. Nock, K.A. Iungerman, R.M. Beaudry, and R.E. Moran. 2005. Harvest date effects on maturity, quality, and storage disorders of 'Honeycrisp' apples. HortScience 401:164-169.

Watkins, C.B., J.F. Nock, S.A. Weis, S. Jayanty, and R.M. Beaudry. 2004. Storage temperature, diphenylamine, and pre-storage delay effects on soft scald, soggy breakdown and bitter pit of 'Honeycrisp' apples. Postharvest Biol. Technol. 322:213-221

Yang, J., D.J. Greenwood, D.L. Rowell, G.A. Wadsworth, and I.G. Burns. 2000. Statistical methods for evaluating a crop nitrogen simulation model, N_ABLE. Agr. Syst. 641: 37-53.

Zhang, Y., P. Li, and L. Cheng. 2010. Developmental changes of carbohydrates, organic acids, amino acids, and phenolic compounds in 'Honeycrisp' apple flesh. Food Chem. 123:1013-1018 